\title{
The role of grass volatiles on oviposition site selection by Anopheles arabiensis and Anopheles coluzzii
}

\author{
Yelfwagash Asmare ${ }^{1,2}$, Sharon R. Hill ${ }^{3}$, Richard J. Hopkins ${ }^{4}$, Habte Tekie ${ }^{1}$ and Rickard Ignell ${ }^{3^{*}}$ (I)
}

\begin{abstract}
Background: The reproductive success and population dynamics, of Anopheles malaria mosquitoes is strongly influenced by the oviposition site selection of gravid females. Mosquitoes select oviposition sites at different spatial scales, starting with selecting a habitat in which to search. This study utilizes the association of larval abundance in the field with natural breeding habitats, dominated by various types of wild grasses, as a proxy for oviposition site selection by gravid mosquitoes. Moreover, the role of olfactory cues emanating from these habitats in the attraction and oviposition stimulation of females was analysed.

Methods: The density of Anopheles larvae in breeding sites associated with Echinochloa pyramidalis, Echinochloa stagnina, Typha latifolia and Cyperus papyrus, was sampled and the larvae identified to species level. Headspace volatile extracts of the grasses were collected and used to assess behavioural attraction and oviposition stimulation of gravid Anopheles arabiensis and Anopheles coluzzii mosquitoes in wind tunnel and two-choice oviposition assays, respectively. The ability of the mosquitoes to differentiate among the grass volatile extracts was tested in multi-choice tent assays.

Results: Anopheles arabiensis larvae were the most abundant species found in the various grass-associated habitats. The larval densities described a hierarchical distribution, with Poaceae (Echinochloa pyramidalis and Echinochloa stagnina)-associated habitat sites demonstrating higher densities than that of Typha-associated sites, and where larvae were absent from Cyperus-associated sites. This hierarchy was maintained by gravid An. arabiensis and An. coluzzii mosquitoes in attraction, oviposition and multi-choice assays to grass volatile extracts.
\end{abstract}

Conclusions: The demonstrated hierarchical preference of gravid An. coluzzii and An. arabiensis for grass volatiles indicates that vegetation cues associated with larval habitats are instrumental in the oviposition site choice of the malaria mosquitoes. Identifying volatile cues from grasses that modulate gravid malaria mosquito behaviours has distinct potential for the development of tools to be used in future monitoring and control methods.

Keywords: Anopheles arabiensis, Anopheles coluzzii, Oviposition, Habitat, Selection, Olfaction, Attraction

\section{Background}

Oviposition site selection by gravid Anopheles malaria mosquitoes is a key moment in the reproductive success of the individual, and thus the population dynamics of the species [1,2]. Consequently, the search for an

\footnotetext{
*Correspondence: rickard.ignell@slu.se

${ }^{3}$ Department of Plant Protection Biology, Unit of Chemical Ecology,

Swedish University of Agricultural Sciences, Alnarp, Sweden

Full list of author information is available at the end of the article
}

oviposition site has important implications with regard to the control of malaria vectors [2]. When insects select oviposition sites, they make choices on increasingly fine spatial scales, starting with selecting a habitat in which to search [3-5]. In the case of egg-laying mosquitoes, they may have to leave a habitat in which they have been acquiring blood meals, in order to enter a habitat containing egg-laying sites. These habitats differ in physical, chemical and biological characteristics providing cues for the searching female, directly influencing the 
distribution, survival and abundance of mosquito larval populations [6-10]. The usage of an oviposition site by mosquitoes is dependent on their relative position in the landscape $[8,11]$, visual cues $[12,13]$, water vapour plumes [14], semiochemical cues associated with water bodies [15-18] and the physical parameters of the water $[6,7]$.

The most productive natural larval habitat types for Anopheles gambiae/Anopheles coluzzii and Anopheles arabiensis are transient puddles [1], often surrounded by short grasses $[7,9,19,20]$. Both of these major vectors in sub-Saharan Africa have also been recorded in more stable water bodies, such as the littoral zone of lakes and in swamps [1, 19, 21-23]. Vegetation often populates these wetland habitats $[1,19,23]$, and An. gambiae/An. coluzzii and An. arabiensis are commonly found amongst cattails (Typha spp.; Typhaceae) and dallis grasses (Paspalum spp.; Poaceae) [24-26]. In contrast, habitats populated by reeds (Phragmites spp.; Poaceae) and papyrus (Cyperus papyrus; Cyperaceae) generally produce low numbers of mosquitoes $[19,27,28]$, probably due to the natural oil production of these species that reduces larval survivorship $[29,30]$. Hence, grasses appear to play an important role in the natural breeding site selection of $A n$. arabiensis and An. gambiae/An. coluzzii. Yet, the influence of natural grasses and other emergent vegetation on the oviposition site selection by gravid female Anopheles mosquitoes is not clearly understood. Moreover, the nature of the volatiles emitted from wild grasses and how they affect the behaviour of An. arabiensis and An. gambiae/ $A n$. coluzzii has not been investigated to date.

The objective of this study was to investigate anopheline larval occurrence and abundance in natural breeding habitats populated by four wild grass species: antelope grass, Echinochloa pyramidalis (Poaceae); hippo grass, Echinochloa stagnina (Poaceae); common cattail; Typha latifolia (Typhaceae); and papyrus reed, C. papyrus (Cyperaceae), and to correlate the behavioural response of gravid An. arabiensis and An. coluzzii to the natural volatiles collected from these grasses. The implications for anopheline ecology and vector management are discussed.

\section{Methods}

\section{Anopheles larval density in habitats with emergent grass species \\ Study sites and sampling procedure}

Anopheles larval sampling was made in potential breeding habitats at the southern littoral region of, and wetlands adjacent to, Lake Tana, Ethiopia $\left(11^{\circ} 37^{\prime} \mathrm{N}, 37^{\circ} 21^{\prime} \mathrm{E}\right.$; $1830 \mathrm{~m}$ above sea level). The climate of the study area is typical of semi-arid regions close to the equator, with a high diurnal temperature variation between daytime extremes of $30{ }^{\circ} \mathrm{C}$ to night time lows of $6{ }^{\circ} \mathrm{C}$, but mainly varies between 20 and $27{ }^{\circ} \mathrm{C}$. Rainfall is on average $1440 \mathrm{~mm}$ per year, falling in one rainy season from May to October, with a peak during July-August [31]. During the El Niño event of 2014-2015, this region experienced a severe drought, with an overall reduction in rainfall of on average 50\% [32], which had a drastic effect on Anopheles mosquito populations. For this reason, larvae of all stages, rather than first instars alone, were collected once in early September and again in late September, in an attempt to sample during the main proliferation period of mosquitoes in the study area.

Cyperus papyrus and T. latifolia are among the dominant grasses in deep water bodies of the lakeshore, whereas E. pyramidalis and E. stagnina predominantly are found at the edge of the lakeshore or in wetlands adjacent to the lake. In the study area, 10 sub-sites dominated by each individual grass species were selected. In each sub-site, 10 separate samplings of larvae (technical replicates) were made using a standard $350 \mathrm{ml}$ dipper [33]. The collected Anopheles larvae were counted and recorded for each larval habitat associated with the different grass species. Of the collected larvae, $10 \%$ were preserved in $70 \%$ ethanol for subsequent identification to species using standard PCR analysis [34].

\section{Data analysis}

The data from the larval survey were subjected to a univariate general linear model (GLM), using the statistical software IBM SPSS Statistics for Windows, Version 21.0. Significant differences between means were determined at $\alpha=0.05$ and post hoc multiple comparisons among the grasses were made using the Tukey's HSD test.

\section{Behavioural response of gravid mosquitoes to grass volatiles Headspace odour collection}

Freshly cut grass $(100 \mathrm{~g})$, including the vegetative and reproductive parts, was enclosed in a Teflon bag (Toppits, Cofresco, Germany). A charcoal-filtered continuous airstream $\left(11 \mathrm{~min}^{-1}\right)$ was drawn by a Personal Air Sampler (PAS-500, Spectrex, Redwood City, CA, USA) over the grass onto an aeration column for $2 \mathrm{~h}$. Aeration columns were made of Teflon tubing $(4.5 \mathrm{~cm} \times 3 \mathrm{~mm}$ i.d.), holding 50 mg Porapak Q (50/80 mesh; Waters Associates, Milford, MA, USA) between glass wool plugs. The columns were rinsed with $1 \mathrm{ml}$ re-distilled $n$-hexane (Merck, Darmstadt, Germany) before use. Adsorbed volatiles were eluted with $300 \mu \mathrm{l}$ re-distilled $n$-hexane. Odour collections from each grass species were pooled separately and then stored in sealed glass capillary tubes at $-20{ }^{\circ} \mathrm{C}$ until used for behavioural experiments. 


\section{Mosquito rearing}

Anopheles arabiensis (Dongola strain) and An. coluzzii (Suakoko strain) were kept at $27 \pm 1{ }^{\circ} \mathrm{C}, 70 \pm 5 \% \mathrm{RH}$, and at a $12 \mathrm{~h}: 12 \mathrm{~h}$ light:dark photoperiod. Larvae were reared in plastic trays $(22 \mathrm{~cm} \times 34 \mathrm{~cm} \times 10 \mathrm{~cm})$ filled with 11 distilled water, and fed powdered Tetramin ${ }^{\circledR}$ fish food (Tetrawerke, Melle, Germany) daily. Pupae (80-100) were placed in BugDorm-1 insect cages $(30 \mathrm{~cm} \times 30 \mathrm{~cm} \times 30 \mathrm{~cm}$; Mega View Science, Taiwan) for adult emergence. Adult males and females were kept together and provided ad libitum access to $10 \%$ sucrose solution. For colony maintenance, female mosquitoes were blood fed on de-fibrinated sheep blood via a membrane-feeding system (Discover Workshops, Accrington, UK). Eggs were laid in $30 \mathrm{ml}$ plastic cups (Nolato Hertila, Sweden) filled with distilled water, and then transferred to larval trays for hatching. For experiments, female mosquitoes, 4 days post-emergence, were allowed access to sheep blood (Håtunalab, Bro, Sweden) from an artificial feeder (Hemotek Discovery Workshops, Accrington, UK) for $3 \mathrm{~h}$. Engorged females 6-8 h post-blood meal were then transferred to a new cage until used for experiments.

\section{Wind tunnel bioassay}

Attraction of An. arabiensis and An. coluzzii to the headspace odour extracts of the four grass species was analysed in a wind tunnel assay [35]. Cotton rolls (DAB Dental AB, Upplands Väsby, Sweden) were used as dispensers, and the amount of extract pipetted onto the dispensers corresponded to the amount of volatiles released during 0.04, 0.4, 4, 10 and $20 \mathrm{~min}$ from the individual grass species. An equivalent amount of $n$-hexane was used as a control. Both treatment and control dispensers were suspended from a $5 \mathrm{~cm}$ wire coil at the upwind end of the wind tunnel. Ten individual female mosquitoes, $48 \mathrm{~h}$ post-blood meal, were transferred to a release cage $2 \mathrm{~h}$ prior to experiments. The chambers were then placed in the downwind end of the wind tunnel, where the insects were allowed 5 min to adapt, before the butterfly valve of the cage was opened for their release. Attraction to either treatment or control was analysed as the proportion of mosquitoes that made source contact within $1 \mathrm{~min}$ after release. Each release rate for each grass volatile extract and the control was replicated ten times.

\section{Oviposition bioassay}

The oviposition response of $A n$. arabiensis and $A n$. coluzzii to the volatile extracts of the four grass species was analysed in BugDorm-1 insect cages kept in a climate-controlled room at $25{ }^{\circ} \mathrm{C}, 70 \pm 5 \% \mathrm{RH}$, and at a 12 h:12 h light:dark photoperiod. Plastic cups $(30 \mathrm{ml}$; Nolato Hertila) filled with $10 \mathrm{ml}$ distilled water provided the oviposition substrate, and were located in opposite corners of the cage, $2 \mathrm{~cm}$ from each wall. The treatment cups were conditioned with one of the wild grass volatile extracts, in the same amounts used in the wind tunnel bioassay. An equivalent amount of $n$-hexane was used as a control. Treatment and control cups were exchanged in between each experiment. Ten mosquitoes, $48 \mathrm{~h}$ postblood meal, were released into the experimental cages at 08:00-10:00, and the number of eggs in the treatment and control cups counted after $48 \mathrm{~h}$. An oviposition index was determined by: (number of eggs laid in treatment cup - number of eggs laid in control cup)/(total number of eggs within the experimental cage). Each release rate of each grass volatile extract was replicated 5 times.

\section{Tent bioassay}

Greenhouse cage tents $(2 \mathrm{~m} \times 2 \mathrm{~m} \times 2 \mathrm{~m}$; BioQuip, Rancho Domniguez, CA, USA) were used as multiarray bioassays to analyse the oviposition preference of $A n$. arabiensis and $A n$. coluzzii to the four wild grass volatile extracts and a control. The tents were kept in a greenhouse at $27 \pm 1{ }^{\circ} \mathrm{C}, 50 \pm 5 \% \mathrm{RH}$, and at a $12 \mathrm{~h}: 12 \mathrm{~h}$ light:dark photoperiod. As above, $30 \mathrm{ml}$ plastic cups filled with $10 \mathrm{ml}$ distilled water provided the oviposition substrate. Treatment cups were conditioned with the four wild grass volatile extracts in an amount corresponding to the volatiles released during $0.4 \mathrm{~min}$ from the individual grass species, while the control cup was conditioned with the equivalent amount of $n$-hexane. Treatment and control cups were set up in a $5 \times 5$ matrix $(20 \mathrm{~cm}$ between cups). The matrix was changed in between replicates ( $\mathrm{n}=10$ for each Anopheles species) to avoid position effects of the treatments. Twenty female mosquitoes, $48 \mathrm{~h}$ post-blood fed, were released into the tents, and the number of eggs counted after $24 \mathrm{~h}$. The oviposition response was scored by counting the number of eggs in the treatment and control cups.

\section{Data analysis}

The behavioural responses of gravid $A n$. coluzzii and $A n$. arabiensis in the wind tunnel and two-choice oviposition bioassay were analysed using a nominal logistic fit model, in which choice was the dependent variable, weighted by the number of (1) mosquitoes in the attraction assays and (2) eggs laid in the oviposition assays, with dose as the independent fixed effect and replicate as a random effect (JMP ${ }^{\circledR}$ Pro 12.0.1. SAS Institute Inc., Cary, NC, USA). In the tent experiments (5-choice oviposition assays), the number of eggs was used as the weight, the choice as the dependent variable, the grasses and control as the independent fixed effect, and the tent and replicates as the random effects. The $X^{2}$ and $P$ value from the likelihood ratio test are reported here. Significant differences between the individual doses (wind tunnel and 
two-choice assays) and grasses (five-choice assay) were determined by odds ratio pairwise comparisons.

\section{Results}

Anopheles arabiensis larval density in natural grass habitats No significant effect of sub-site location was found $\left(F=0.367, D F_{d}=9, D F_{n}=3, P=0.999\right)$. Hence, the larval abundance data collected from the breeding habitats associated with each grass species was pooled in subsequent analysis. Anopheles arabiensis was the most abundant species comprising more than $40 \%$ of the specimens in the study area, and was the only member of the $A n$. gambiae sensu lato complex to be identified following PCR analyses of 48 mosquito larvae.

A significantly higher number of An. arabiensis larvae were found in E. pyramidalis dominated breeding habitats than in any of the other potential breeding habitats (Fig. 1). The number of larvae in the remaining habitats also differed significantly, with breeding habitats dominated by $E$. stagnina containing more larvae than breeding habitats dominated by T. latifolia (Fig. 1). Interestingly, no larvae were found in habitats dominated by C. papyrus (Fig. 1).

\section{Attraction of An. arabiensis and An. coluzzii to grass volatiles}

Attraction of An. arabiensis and An. coluzzii to the grass volatile extracts was dose dependent and differed among the grass species (An. arabiensis: Dose, $X^{2}=34.51, P<0.0001$; Grass, $X^{2}=13.11, P=0.0044 ; A n$. coluzzii: Dose, $\chi^{2}=46.25, P<0.0001$; Grass, $\chi^{2}=41.46$, $P<0.0001$ ) (Fig. 2). No significant difference in the attraction of An. arabiensis to the volatile extracts of $E$. pyramidalis, E. stagnina and T. latifolia was found, however, the attraction to the $C$. papyrus volatile extract was significantly lower than each of the other grass volatile extracts (Table 1). Attraction of An. coluzzii to the volatile extracts of either the Poaceae (E. pyramidalis and $E$. stagnina), or the Typhaceae (T. latifolia) and Cyperaceae (C. papyrus), did not differ. The attraction to the volatile extract of the Typhaceae and Cyperaceae, however, was significantly lower than that of the Poaceae (Table 1).

\section{Oviposition response of An. arabiensis and An. coluzzii to grass volatiles}

The oviposition response of An. arabiensis and $A n$. coluzzii to water conditioned with the grass volatile extracts was both dose dependent and differed among the grass species (An. arabiensis: Dose, $X^{2}=94.67$, $P<0.0001$; Grass, $X^{2}=44.79, P<0.0001 ;$ An. coluzzii: Dose, $X^{2}=47.35, P<0.0001$; Grass, $X^{2}=24.29$, $P<0.0001$ ) (Fig. 3). No significant differences in oviposition response were found for An. coluzzii to water

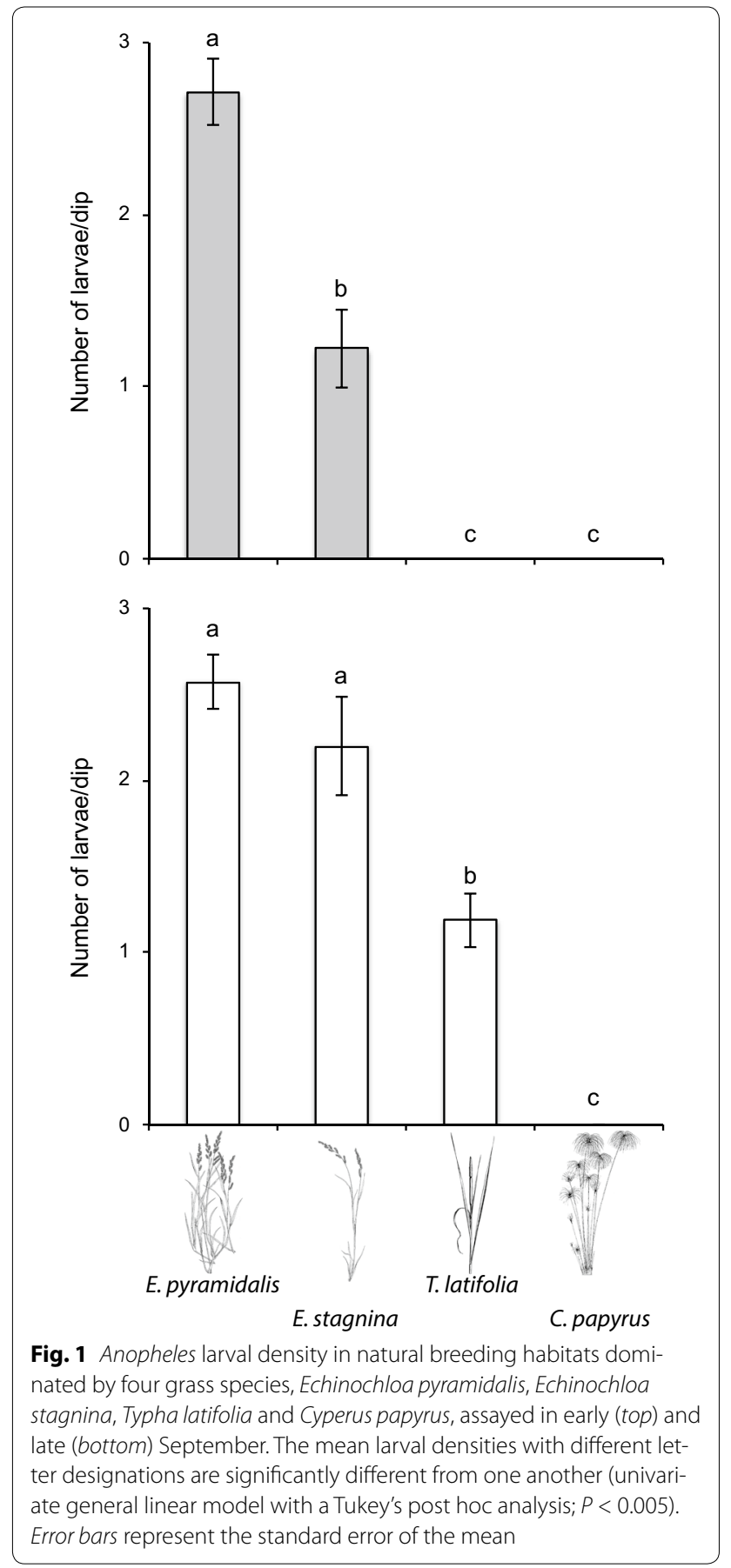

conditioned with volatile extracts of E. pyramidalis, E. stagnina and T. latifolia, but the oviposition response to these grass extracts were significantly higher than that observed for the C. papyrus volatile extract (Table 2). Similarly, for the $C$. papyrus volatile extract, the oviposition response of $A n$. arabiensis was significantly lower than to that of all the other grass volatile extracts (Table 2). In contrast to An. coluzzii, the volatile extract 


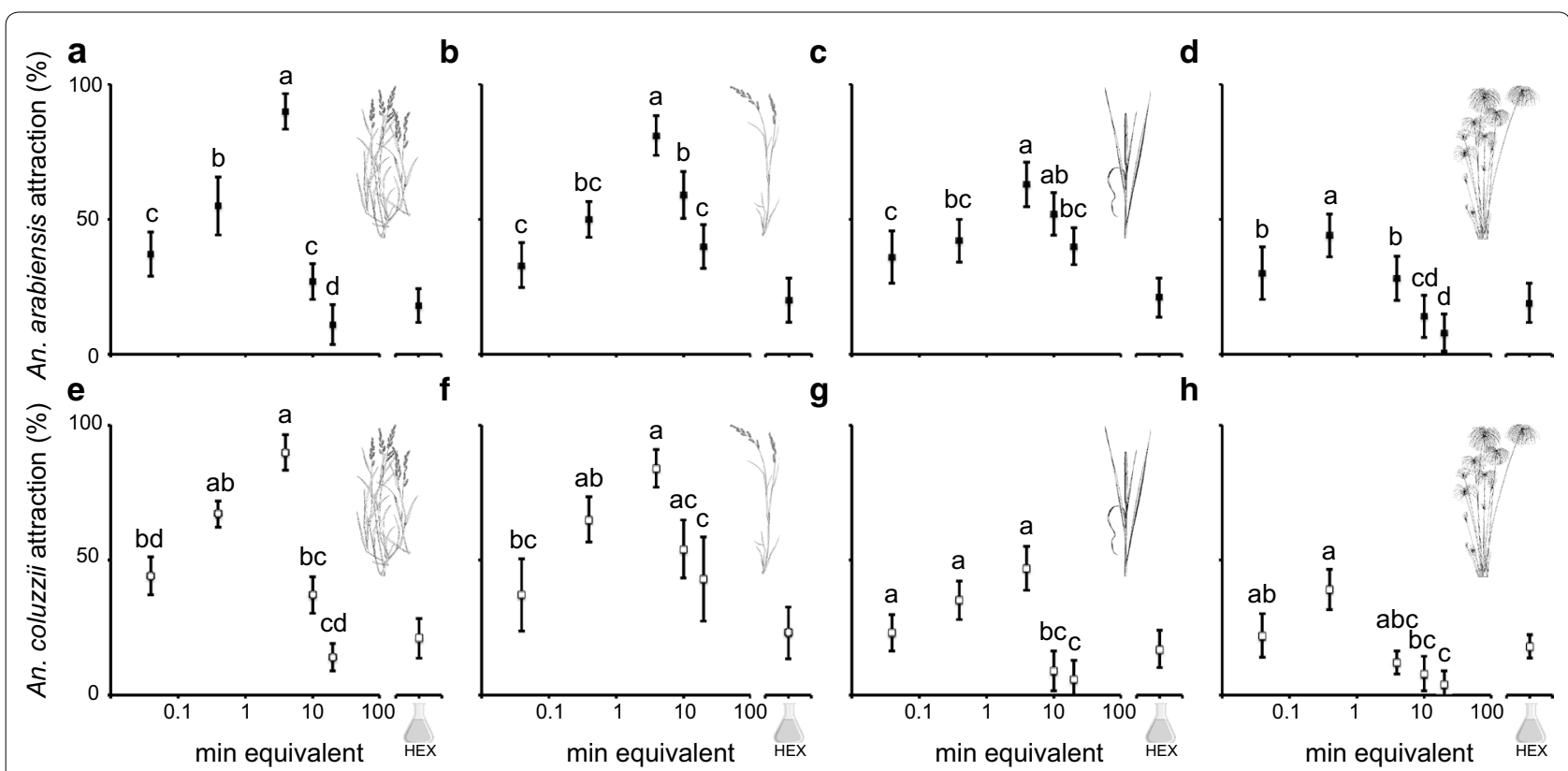

Fig. 2 Attraction of gravid Anopheles arabiensis and Anopheles coluzzii to grass volatile headspace extracts, from Echinochloa pyramidalis (a, e) Echinochloa stagnina $(\mathbf{b}, \mathbf{f})$, Typha latifolia $(\mathbf{c}, \mathbf{g})$ and Cyperus papyrus $(\mathbf{d}, \mathbf{h})$, respectively. Release rate of the volatile headspace extracts is given in minute equivalents. The solvent control was hexane (HEX). The mean percent attraction values with the same letters indicate no significant difference from one another (nominal logistic fit model, $X^{2}$ and $P<0.05$ from the likelihood ratio test, significant differences were determined by odds ratio pairwise comparisons). Error bars represent the standard error of the mean

Table 1 Cross-comparative analysis of the attraction of gravid mosquitoes to volatile extracts of grass species

\begin{tabular}{|c|c|c|c|c|c|}
\hline \multirow[b]{3}{*}{ Level 1} & \multirow[b]{3}{*}{ Level 2} & \multicolumn{4}{|l|}{ Attraction } \\
\hline & & \multicolumn{2}{|c|}{ An. arabiensis } & \multicolumn{2}{|l|}{ An. coluzzii } \\
\hline & & Odds ratio & $P$ & Odds ratio & $P$ \\
\hline E. pyramidalis & E. stagnina & 0.8361 & 0.3210 & 0.8929 & 0.5313 \\
\hline E. pyramidalis & T. Iatifolia & 0.9226 & 0.6546 & 2.011 & 0.0002 \\
\hline E. pyramidalis & C.papyrus & 1.553 & 0.0181 & 2.431 & $<0.0001$ \\
\hline E. stagnina & T. latifolia & 1.103 & 0.5802 & 2.252 & $<0.0001$ \\
\hline E. stagnina & C.papyrus & 1.858 & 0.0007 & 2.722 & $<0.0001$ \\
\hline T. latifolia & C.papyrus & 1.684 & 0.0045 & 1.209 & 0.3436 \\
\hline
\end{tabular}

The analysis is done using a nominal logistic regression model fit $a=0.05$

of T. latifolia stimulated a lower oviposition response in An. arabiensis than that of E. pyramidalis (Table 2).

\section{Tent experiments response}

In the five-choice oviposition assay, the overall oviposition preference hierarchy of both Anopheles species to the grass volatile extracts was found to be E. pyramidalis $>$ E. stagnina $\geq$ T. latifolia $=$ C. papyrus (Fig. 4). Water conditioned with volatile extracts of either $E$. pyramidalis or E. stagnina, elicited a significantly higher oviposition response than the control in both $A n$. arabiensis and $A n$. coluzzii, while that of $T$. latifolia elicited a significantly higher response than the control in An. arabiensis alone (Fig. 4). In contrast, the oviposition response of $A n$. coluzzii to water conditioned with volatile extracts of $T$. latifolia, as well as that of C. papyrus, was significantly lower than that of the control.

\section{Discussion}

Field collection of An. arabiensis larvae indicated a role for emergent vegetation in the oviposition site selection and survival of malaria mosquitoes. Larval densities were highest in Poaceae-associated habitats, much lower in Typha-associated sites and absent from Cyperus-associated sites. One potential mechanism regulating the differential distribution of larvae may be an odour-based oviposition site selection preference. Gravid female $A n$. arabiensis and An. coluzzii were, indeed, found to be differentially attracted to all grass volatile extracts, yet were only stimulated to oviposit on water conditioned with Poaceae volatile extracts. This was further supported by multi-choice oviposition assays revealing that both species demonstrated a preference hierarchy among the grass volatiles, E. pyramidalis $>E$. stagnina $>T$. latifolia $\geq$ C. papyrus. These findings may also reflect the abundance of available nutrients and toxins associated with these potential larval habitats, which may affect 


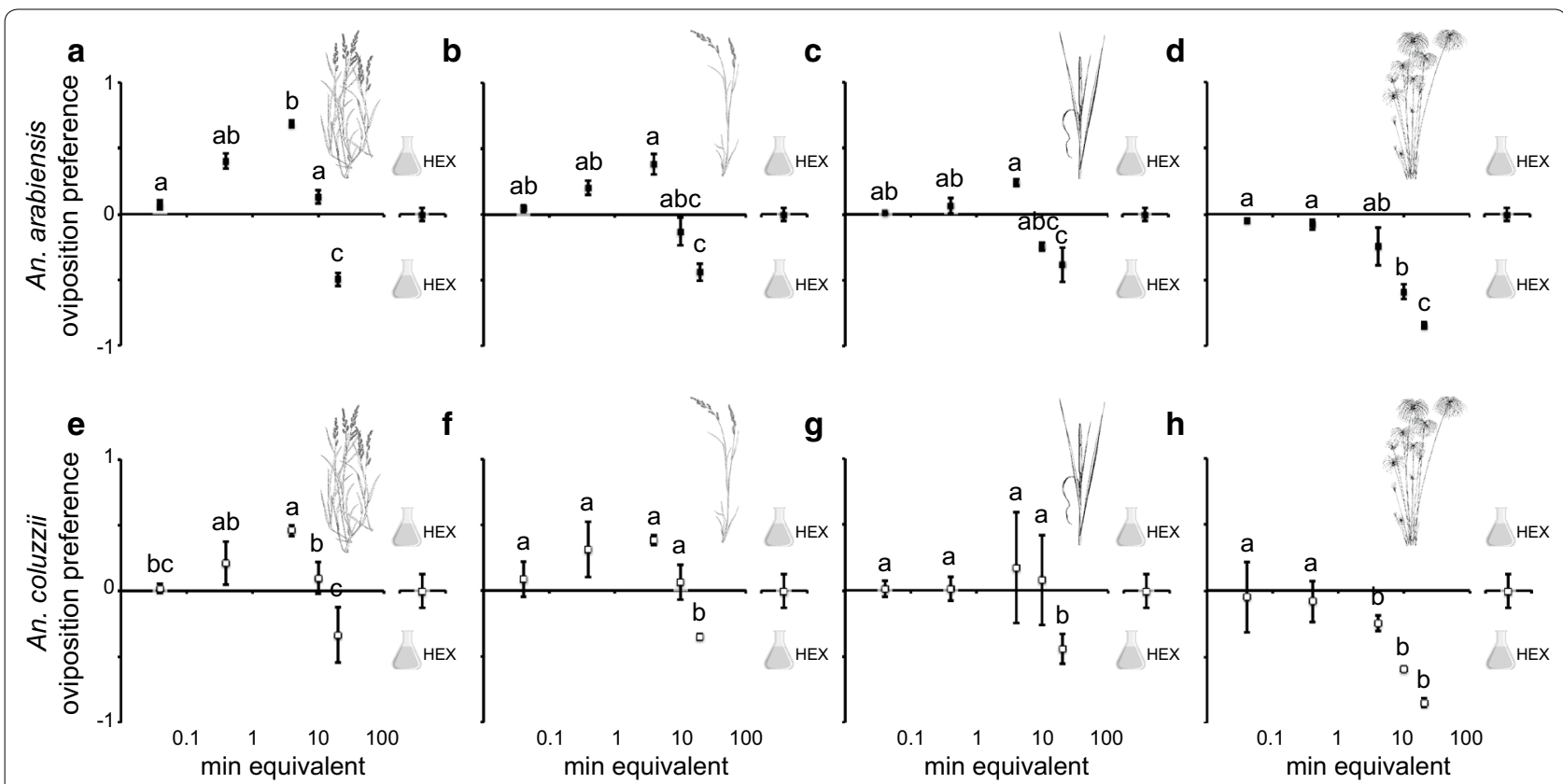

Fig. 3 Oviposition response of gravid Anopheles arabiensis and Anopheles coluzzii to grass volatile headspace extracts, from Echinochloa pyramidalis $(\mathbf{a}, \mathbf{e})$ Echinochloa stagnina $(\mathbf{b}, \mathbf{f})$, Typha latifolia $(\mathbf{c}, \mathbf{g})$ and Cyperus papyrus $(\mathbf{d}, \mathbf{h})$, respectively. Release rate of the volatile headspace extracts is given in minute equivalents. The solvent control was hexane (HEX). Mean oviposition preferences with the same letters indicate no significant difference from one another (nominal logistic fit model, $X^{2}$ and $P<0.05$ from the likelihood ratio test, significant differences were determined by odds ratio pairwise comparisons). Error bars represent the standard error of the mean

Table 2 Cross-comparative analysis of the oviposition response of gravid mosquitoes to volatile extracts of grass species

\begin{tabular}{|c|c|c|c|c|c|}
\hline \multirow[b]{3}{*}{ Level 1} & \multirow[b]{3}{*}{ Level 2} & \multicolumn{4}{|l|}{ Oviposition } \\
\hline & & \multicolumn{2}{|c|}{ An. arabiensis } & \multicolumn{2}{|l|}{ An. coluzzii } \\
\hline & & Odds ratio & $P$ & Odds ratio & $P$ \\
\hline E. pyramidalis & E. stagnina & 0.8425 & 0.0687 & 1.005 & 0.9556 \\
\hline E. pyramidalis & T. latifolia & 0.7780 & 0.0076 & 0.8700 & 0.1261 \\
\hline E. pyramidalis & C.papyrus & 0.5364 & $<0.0001$ & 0.6800 & $<0.0001$ \\
\hline E. stagnina & T. latifolia & 0.9233 & 0.3932 & 0.8657 & 0.1043 \\
\hline E.stagnina & C.papyrus & 0.6366 & $<0.0001$ & 0.6766 & $<0.0001$ \\
\hline T. latifolia & C. papyrus & 0.6894 & $<0.0001$ & 0.7816 & 0.0067 \\
\hline
\end{tabular}

The analysis is done using a nominal logistic regression model fit $a=0.05$

larval survival differentially in the various grass-associated habitats.

Emergent vegetation in aquatic habitats are commonly associated with the presence or absence of An. gambiae/ An. coluzzii and An. arabiensis larvae [1, 7, 9, 19, 23, 36]. While the number of Anopheles larvae collected in this study were low, due to the impact of El Niño in the study area in 2014-2015, the observed patterns of association with vegetation are consistent with previous reports [9, $19,24]$. In studies in which the vegetation has been characterised, habitats associated with Poaceae generally have a higher An. gambiae/An. coluzzii and An. arabiensis larval density compared with that of habitats associated with Typhaceae and Cyperaceae $[9,19,24]$. While vegetation in these habitats is known to influence characteristics, such as shading, temperature, water flow, predator abundance and nutrients, they also provide gravid mosquitoes with chemical cues important to habitat selection.

An increasing body of evidence suggests that anopheline mosquitoes make use of olfactory cues as positive indicators for oviposition site selection [18, 37-39]. While the focus of this study was not to identify the specific salient volatiles in these attractive and aversive grasses, the behavioural results presented here indicate a strong and robust preference for the headspace extracts of the Poaceae grasses. Interestingly, the majority of the previously identified olfactory cues that drive the oviposition site selection in An. gambiae s.l. originate from wild and cultivated grasses of the Poaceae family [37-39]. These odours include $\alpha$ - and $\beta$-pinene, 3-carene, caryophyllene, limonene and nonanal [18, 38-41], which are not affected by mechanical damage of the plants, but are thought to be constitutively expressed [42-44]. Future work will be aimed at identifying the salient volatiles in 


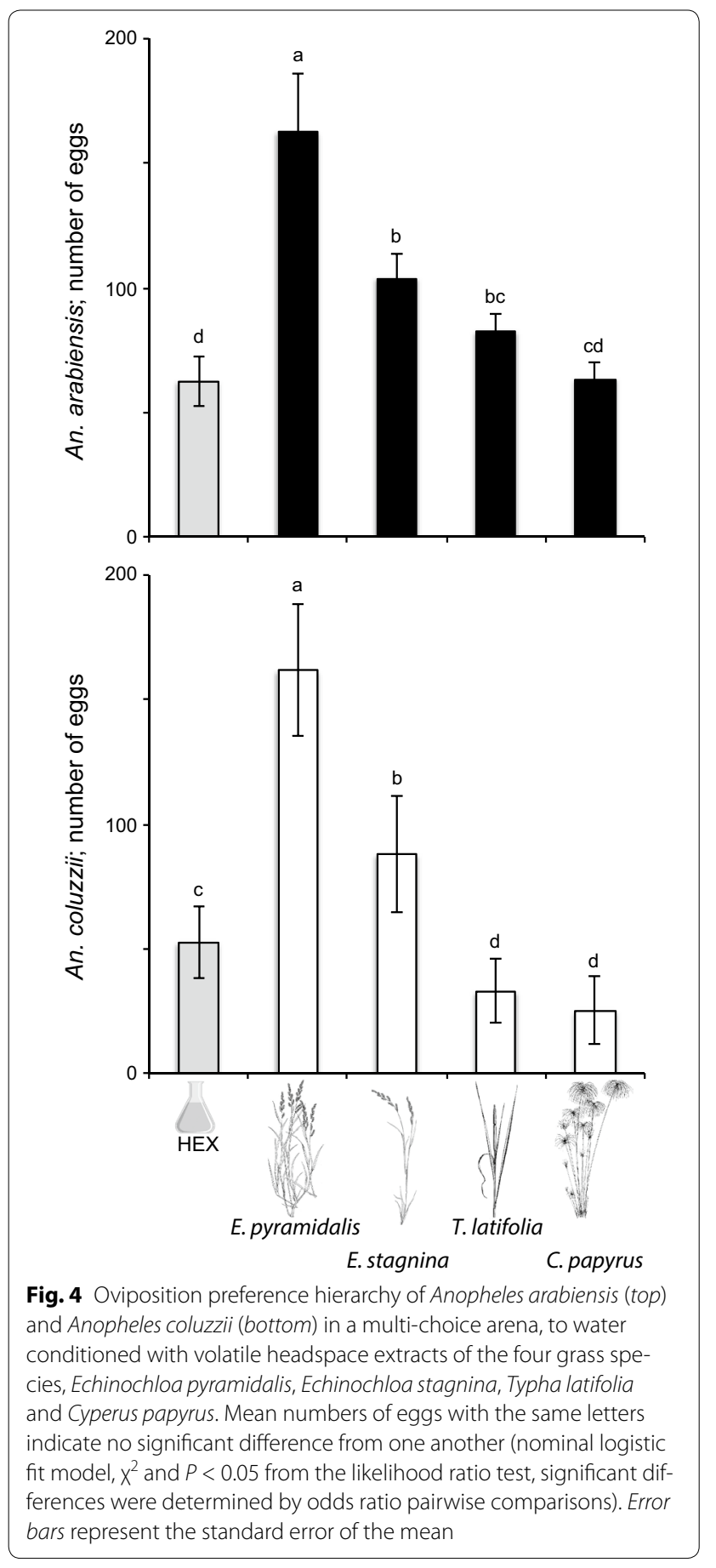

the grasses that elicited attraction in gravid anophelines in this study.

Anopheles mosquitoes are likely differentially attracted to larval habitats that are rich in nutrients, derived directly from shed pollen [45-47] and indirectly from accumulated detritus and associated micro-organisms, and that provide shelter from abiotic and biotic threats [48]. Nutrients derived from shed maize pollen, which are rich in water soluble proteins [49], have been shown to enhance larval development and growth, adult size and survival $[45,46]$. While pollen of other grass species might also constitute a supplemental nutriment for surface feeding anophelines, the nutritive quality of grass pollen varies across species [50, 51]. For example, typha pollen is known to be nutrient poor compared with maize pollen [50, 51]. Females that select larval habitats associated with grasses shedding nutrient rich pollen have the potential to increase their own fitness by providing their offspring with selective advantages, as previously shown for maize pollen. Selective pressures may also be involved in the avoidance of C. papyrus-associated habitats by gravid anophelines, as this grass secretes essential oils that create a thin film on the surface of the water, preventing mosquito larvae from breathing $[29,30]$.

\section{Conclusions}

The demonstrated hierarchical preference of gravid An. coluzzii and An. arabiensis for grasses indicates that vegetation types associated with larval habitats are instrumental in the oviposition choice of the malaria mosquitoes. Current and future analysis of Anopheles oviposition ecology associated with grasses is likely to provide key larval habitat characteristics that may be integrated into current methods of larval control. Also, identifying volatile cues from grasses that modulate gravid malaria mosquito behaviours has distinct potential for the development of tools to be used in future monitoring and control methods.

\section{Abbreviations}

DF: degrees of freedom; GLM: generalised linear model; HSD: honest significant difference; PCR: polymerase chain reaction; $\mathrm{RH}$ : relative humidity; $\mathrm{X}^{2}$ : Chi squared.

\section{Authors' contributions}

$\mathrm{RI}, \mathrm{RH}$ and $\mathrm{SRH}$ designed the study. RI and SRH supervised and YA conducted the experiments. SRH and YA conducted the statistical analyses. YA produced the original draft, while $\mathrm{RI}, \mathrm{SRH}$ and $\mathrm{RH}$ critically revised the manuscript. All authors read and approved the final manuscript.

\section{Author details}

${ }^{1}$ Department of Zoological Sciences, Addis Ababa University, PO. Box 1176, Addis Ababa, Ethiopia. ${ }^{2}$ Department of Biological Sciences, Debre Markos University, Debre Markos, Ethiopia. ${ }^{3}$ Department of Plant Protection Biology, Unit of Chemical Ecology, Swedish University of Agricultural Sciences, Alnarp, Sweden. ${ }^{4}$ Natural Resources Institute, University of Greenwich, London, UK.

\section{Acknowledgements}

Addis Ababa University and Debre Markos University are duly acknowledged for facilitating the study. The authors are grateful to the local communities in the shoreline villages of Lake Tana for their cooperation during grass volatile collection and larval sampling. The authors wish to extend their heartfelt acknowledgements to the late Dr. Emiru Seyoum for his involvement in the early stages of study design and implementation, and for his wisdom.

\section{Competing interests}

The authors declare that they have no competing interests. 


\section{Availability of data and materials}

The data sets supporting the conclusions of this article are provided in the manuscript.

\section{Funding}

This study was financially supported by a grant from the Swedish International Development Cooperation Agency, "Chemo-ecological management of Anopheles arabiensis" (SWE-2009-113) to RI.

Received: 19 August 2016 Accepted: 31 January 2017

Published online: 07 February 2017

\section{References}

1. Ndenga BA, Simbauni JA, Mbugi JP, Githeko AK, Fillinger U. Productivity of malaria vectors from different habitat types in the western Kenya highlands. PLOS ONE. 2011;6:e19473.

2. White MT, Griffin JT, Churcher TS, Ferguson NM, Basáñez M-G, Ghani AC, et al. Modelling the impact of vector control interventions on Anopheles gambiae population dynamics. Parasit Vectors. 2011;4:153.

3. Hambäck PA, Björkman M, Rämert B, Hopkins RJ. Scale-dependent responses in cabbage herbivores affect attack rates in spatially heterogeneous systems. Basic Appl Ecol. 2009;10:228-36.

4. Raffa KF, Andersson MN, Schlyter F. Host selection by bark beetles: playing the odds in a high-stakes game. Adv Insect Physiol. 2016;50:1-74

5. Webster B, Cardé RT. Use of habitat odour by host-seeking insects. Biol Rev. 2016. doi:10.1111/brv.12281.

6. Gimnig JE, Ombok M, Kamau L, Hawley WA. Characteristics of larval anopheline (Diptera: Culicidae) habitats in western Kenya. J Med Entomol. 2001;38:282-8.

7. Minakawa N, Sonye G, Mogi M, Yan G. Habitat characteristics of Anopheles gambiae s.s. larvae in a Kenyan highland. Med Vet Entomol. 2004;18:301-5.

8. Vanwambeke SO, Somboon P, Harbach R, Isenstadt M, Lambin EF, Walton C, et al. Landscape and land cover factors influence the presence of Aedes and Anopheles larvae. J Med Entomol. 2007;44:133-44.

9. Fillinger U, Sombroek H, Majambere S, van Loon E, Takken W, Lindsay SW. Identifying the most productive breeding sites for malaria mosquitoes in The Gambia. Malar J. 2009:8:62

10. Ndenga BA, Simbauni JA, Mbugi JP, Githeko AK. Physical, chemical and biological characteristics in habitats of high and low presence of anopheline larvae in western Kenya highlands. PLoS ONE. 2012;7:e47975.

11. Mushinzimana E, Munga S, Minakawa N, Li L, Feng C-C, Bian L, et al. Landscape determinants and remote sensing of anopheline mosquito larval habitats in the western Kenya highlands. Malar J. 2006;5:13.

12. Dugassa S, Lindh JM, Torr SJ, Oyieke F, Lindsay SW, Fillinger U. Electric nets and sticky materials for analysing oviposition behaviour of gravid malaria vectors. Malar J. 2012;11:374

13. Dugassa S, Lindh JM, Torr SJ, Lindsay SW, Fillinger U. Evaluation of the influence of electric nets on the behaviour of oviposition site seeking Anopheles gambiae s.s. Parasit Vectors. 2014;7:272.

14. Okal MN, Francis B, Herrera-Varela M, Fillinger U, Lindsay SW. Water vapor is a pre-oviposition attractant for the malaria vector Anopheles gambiae sensu stricto. Malar J. 2013;12:365.

15. Rejmánková E, Higashi R, Grieco J, Achee N, Roberts D. Volatile substances from larval habitats mediate species-specific oviposition in Anopheles mosquitoes. J Med Entomol. 2005;42:95-103.

16. Sumba LA, Ogbunugafor CB, Deng AL, Hassanali A. Regulation of oviposition in Anopheles gambiae s.s.: role of inter- and intra-specific signals. J Chem Ecol. 2008;34:1430-6

17. Afify A, Galizia CG. Chemosensory cues for mosquito oviposition site selection. J Med Entomol. 2015;52:120-30.

18. Lindh JM, Okal MN, Herrera-Varela M, Borg-Karlson AK, Torto B, Lindsay SW, et al. Discovery of an oviposition attractant for gravid malaria vectors of the Anopheles gambiae species complex. Malar J. 2015;14:119.

19. Fillinger U, Sonye G, Killeen GF, Knols BG, Becher N. The practical importance of permanent and semipermanent habitats for controlling aquatic stages of Anopheles gambiae sensu lato mosquitoes: operational observation from a rural town in western Kenya. Trop Med Int Health. 2004:9:1274-89.
20. Majambere S, Fillinger U, Sayer DR, Green C, Lindsay SW. Spatial distribution of mosquito larvae and the potential for targeted larval control in The Gambia. Am J Trop Med Hyg. 2008;79:19-27.

21. Minakawa N, Munga S, Atieli F, Mushinzimana E, Zhou G, Githeko AK, et al. Spatial distribution of anopheline larval habitats in western Kenyan highlands: effects of land cover types and topography. Am J Trop Med Hyg. 2005;73:157-65.

22. Imbahale SS, Paaijmans KP, Mukabana WR, van Lammeren R, Githeko AK, Takken W. A longitudinal study on Anopheles mosquito larval abundance in distinct geographical and environmental settings in western Kenya. Malar J. 2011:10:81.

23. Minakawa N, Dida GO, Sonye GO, Futami K, Njenga SM. Malaria vectors in Lake Victoria and adjacent habitats in western Kenya. PLoS ONE. 2012;7:e32725.

24. Bøgh C, Clarke SE, Jawara M, Thomas CJ, Lindsay SW. Localized breeding of the Anopheles gambiae complex (Diptera: Culicidae) along the River Gambia, West Africa. Bull Entomol Res. 2003;93:279-87.

25. Gouagna LC, Rakotondranary M, Boyer S, Lempérière G, Dehecq J-S, Fontenille D. Abiotic and biotic factors associated with the presence of Anopheles arabiensis immatures and their abundance in naturally occurring and man-made aquatic habitats. Parasit Vectors. 2012;5:96.

26. Khater El, Sowilem MM, Sallam MF, Alahmed AM. Ecology and habitat characterization of mosquitoes in Saudi Arabia. Trop Biomed. 2013;30:409-27.

27. Goma LKH. Experimental breeding of Anopheles gambiae Giles in papyrus swamps. Nature. 1960;187:1137-8.

28. Yohannes M, Haile M, Ghebreyesus TA, Witten KH, Getachew A, Bayass $P$, et al. Can source reduction of mosquito larval habitat reduce malaria transmission in Tigray, Ethiopia? Trop Med Int Health. 2005; 10:1274-85

29. Mouchet G, Manguin S, Sircoulon G, Laventure S, Faye O, Onapa AW, et al. Evolution of malaria in Africa for the past 40 years: impact of climatic and human factors. J Am Mosq Control Assoc. 1998;14:121-30.

30. Lindsay SW, Martens WJM. Malaria in the African highlands: past, present and future. Bull World Health Organ. 1998:76:33-45.

31. Vijverberg J, Sibbing FA, Dejen E. Lake Tana: source of the Blue Nile. In: Dumont HJ, editor. The Nile Vol 89 Monographiae Biologicae. Netherlands: Springer; 2009. p. 163-92.

32. FAO. FAO in Ethiopia-FAO El Niño response plan. Rome; 2016.

33. World Health Organization. Guidelines for laboratory and field testing of mosquito larvicides. Geneva: World Health Organization; 2005.

34. Scott JA, Brogdon WG, Collins FH. Identification of single specimens of the Anopheles gambiae complex by the polymerase chain reaction. Am J Trop Med Hyg. 1993:49:520-9.

35. Majeed S, Hill SR, Ignell R. Impact of elevated $\mathrm{CO}_{2}$ background levels on the host-seeking behaviour of Aedes aegypti. J Exp Biol. 2014;217:598-604.

36. Mwangangi JM, Mbogo CM, Muturi EJ, Nzovu JG, Githure JI, Yan G, et al. Spatial distribution and habitat characterization of Anopheles larvae along the Kenyan coast. J Vector Borne Dis. 2007:44:44-51.

37. Torres-Estrada JL, Meza-Alvarez RA, Cibrián-Tovar J, Rodriguez-Lopez MH, Arredondo-Jiménez Jl, Cruz-López L, et al. Vegetation-derived cues for the selection of oviposition substrates by Anopheles albimanus under laboratory conditions. J Am Mosq Control Assoc. 2005:21:344-9.

38. Wondwosen B, Birgersson G, Seyoum E, Tekie H, Torto B, Fillinger U, et al. Rice lures gravid malaria mosquitoes. Sci Rep. 2016:6:37930.

39. Wondwosen B, Hill SR, Birgersson G, Seyoum E, Tekie H, Ignell R. A (maize) ing attraction: gravid Anopheles arabiensis are attracted and oviposit in response to maize pollen odours. Malar J. 2017;16:39.

40. He YJ, Yue YD, Tang F, Guo XF, Wang J. Chemical composition and antioxidant capacity of essential oils from different species of the bamboo leaves. Sci Silvae Sin. 2010;46:120-8

41. Köllner TG, Held M, Lenk C, Hiltpold I, Turlings TC, Gershenzon J, et al. A maize (E)- $\beta$-caryophyllene synthase implicated in indirect defense responses against herbivores is not expressed in most American maize varieties. Plant Cell. 2008;20:482-94.

42. von Mérey GE, Veyrat N, D’Alessandro M, Turlings TCJ. Herbivore-induced maize leaf volatiles affect attraction and feeding behavior of Spodoptera littoralis caterpillars. Front Plant Sci. 2013:4:209.

43. Xu T, Zhou Q, Xia Q, et al. Effects of herbivore-induced rice volatiles on the host selection behavior of brown planthopper, Nilaparvata lugens. Chin Sci Bull. 2002:47:1355-60. 
44. Yan Z-G, Wang C-Z. Similar attractiveness of maize volatiles induced by Helicoverpa armigera and Pseudaletia separate to the generalist parasitoid Campoletis chlorideae. Ent Exp Appl. 2006;118:87-96.

45. Ye-Ebiyo Y, Pollack R, Spielman A. Enhanced development in nature of larval Anopheles arabiensis mosquitoes feeding on maize pollen. Am J Trop Med Hyg. 2000;63:90-3.

46. Ye-Ebiyo Y, Pollack RJ, Kiszewski A, Spielman A. Enhancement of development of larval Anopheles arabiensis by proximity to flowering maize (Zea mays) in turbid water and when crowded. Am J Trop Med Hyg. 2003;68:748-52.

47. Ye-Ebiyo Y, Pollack RJ, Kiszewski A, Spielman A. A component of maize pollen that stimulates larval mosquitoes (Diptera: Culicidae) to feed and increases toxicity of microbial larvicides. J Med Entomol. 2003;40:860-4.
48. Merritt RW, Dadd RH, Walker ED. Feeding behavior, natural food, and nutritional relationships of larval mosquitoes. Annu Rev Entomol. 1992;37:349-76.

49. Porter EK. Origins and genetic nonvariability of the proteins which diffuse from maize pollen. Environ Health Prospect. 1981;37:53-9.

50. Schmidt JO, Thoenes SC, Levin MD. Survival of honey bees Apis mellifera (Hymenoptera: Apidae), fed with various pollen sources. Ann Entomol Soc Am. 1987;80:176-83.

51. Roulston TH, Cane JH. Pollen nutritional content and digestibility for animals. Plant Syst Evol. 2000;222:187-209.

\section{Submit your next manuscript to BioMed Central and we will help you at every step:}

- We accept pre-submission inquiries

- Our selector tool helps you to find the most relevant journal

- We provide round the clock customer support

- Convenient online submission

- Thorough peer review

- Inclusion in PubMed and all major indexing services

- Maximum visibility for your research

Submit your manuscript at www.biomedcentral.com/submit 